\title{
Improving evaluation of NO2 emission from ships using spatial association on TROPOMI satellite data
}

\author{
Solomiia Kurchaba \\ s.kurchaba@liacs.leidenuniv.nl \\ Leiden University \\ Leiden, The Netherlands
}

\author{
Jasper van Vliet \\ jasper.van.vliet@ilent.nl \\ Human Environment and Transport \\ Inspectorate (ILT) \\ Utrecht, The Netherlands
}

\author{
Jacqueline J. Meulman \\ jmeulman@math.leidenuniv.nl \\ Leiden University \\ Leiden, The Netherlands \\ Stanford University \\ Stanford, CA, USA
}

\author{
Fons J. Verbeek \\ f.j.verbeek@liacs.leidenuniv.nl \\ Leiden University \\ Leiden, The Netherlands
}

\begin{abstract}
As of 2021, more demanding $\mathrm{NO}_{\mathrm{x}}$ emission requirements entered into force for newly built ships operating on the North and Baltic Sea. Even though various methods are used to assess ships' pollution in ports and off the coastal areas, monitoring over the open sea has been infeasible until now. In this work, we present a novel automated method for evaluation of $\mathrm{NO}_{2}$ emissions produced by individual seagoing ships. We use the spatial association statistic local Moran's I in order to improve the distinguishability between the plume and the background. Using the Automatic Identification Signal (AIS) data of ship locations as well as incorporated uncertainties in wind speed and wind direction, we automatically associate the detected plumes with individual ships. We evaluate the quality of ship-plume matching by calculating the Pearson correlation coefficient between the values of a model-based emission proxy and the estimated $\mathrm{NO}_{2}$ concentrations. For five of the six analyzed areas, our method yields results that are an improvement over the baseline approach used in a previous study.
\end{abstract}

\section{CCS CONCEPTS}

- Applied computing $\rightarrow$ Earth and atmospheric sciences.

\section{KEYWORDS}

TROPOMI, NO2, ships, Moran's I, spatial association, AIS, wind

\section{ACM Reference Format:}

Solomiia Kurchaba, Jasper van Vliet, Jacqueline J. Meulman, Fons J. Verbeek, and Cor J. Veenman. 2021. Improving evaluation of NO2 emission from ships using spatial association on TROPOMI satellite data. In 29th International Conference on Advances in Geographic Information Systems (SIGSPATIAL

This work is licensed under a Creative Commons Attribution-

NonCommercial International 4.0 License.

SIGSPATIAL '21, November 2-5, 2021, Beijing, China

(c) 2021 Copyright held by the owner/author(s).

ACM ISBN 978-1-4503-8664-7/21/11.

https://doi.org/10.1145/3474717.3484213

\author{
Cor J. Veenman \\ c.j.veenman@liacs.leidenuniv.nl \\ Leiden University \\ Leiden, The Netherlands \\ TNO \\ The Hague, The Netherlands
}

'21), November 2-5, 2021, Beijing, China. ACM, New York, NY, USA, 4 pages. https://doi.org/10.1145/3474717.3484213

\section{INTRODUCTION}

Nitrogen oxides $\left(\mathrm{NO}_{\mathrm{x}} \approx \mathrm{NO}+\mathrm{NO}_{2}\right)$ play an important role in air quality. $\mathrm{NO}_{\mathrm{x}}$ is a strong catalyst in tropospheric ozone formation that has serious cumulative impact both on climate and health [10]. Approximately $15 \%$ of total anthropogenic $\mathrm{NO}_{\mathrm{x}}$ emissions originate from shipping [6], [14], [5]. Starting from 2021, the International Maritime Organization (IMO) has further tightened the $\mathrm{NO}_{\mathrm{x}}$ emission constraints for diesel engines of newly built ships operating in the North and Baltic Sea [9].

The currently used compliance monitoring methods include land-based in situ measurements [3], [11], on-board measurements [1], and airborne platform-based assessments [18]. All methods, nevertheless, require a close proximity to ships, are costly, and thus cannot be performed with the desired frequency. As a result, ship compliance monitoring cannot be executed regularly nor on a global scale, especially, once the ship enters the open sea waters.

A potential solution for ship compliance monitoring is to apply remote sensing instruments [16]. So far, however, the information from satellite measurements has been extracted based on multimonth data averaging [4], [15], [20]. Such an approach allows quantification of $\mathrm{NO}_{\mathrm{x}}$ pollution of the shipping industry as a whole, but makes it impossible to evaluate the emission level produced by an individual ship.

In [7], the authors introduced the first attempt to quantify isolated ship plumes that can be identified by visual inspection of daily data. Since the $\mathrm{NO}_{2}$ traces from the majority of the ships in the area are not sufficiently stronger than the $\mathrm{NO}_{2}$ background concentration, only plumes of larger ships were assessable in that study. Moreover, the authors acknowledged that their approach requires multiple manual steps.

In our study, we present a heuristic for automated evaluation of $\mathrm{NO}_{2}$ concentrations resulting from $\mathrm{NO}_{\mathrm{x}}$ emissions produced by individual seagoing ships. The method allows the quantification of the ships' emission, even if the produced plume cannot be distinguished visually, so that performance of more and smaller ships 
can be assessed in a single satellite overpass. The obtained results are benchmarked against the method proposed in [7].

\section{DATA SOURCES}

The approach we are introducing in this study requires integration of three types of data: TROPOMI satellite measurements, information about the positions of ships and wind data. Below we describe in detail all data sources used.

TROPOMI/S5P [19] is a spectrometer on board the Copernicus Sentinel 5 Precursor satellite launched in October 2017. The maximal ground pixel resolution for the instrument equals $5.5 \times 3.5 \mathrm{~km}^{2}$, which is significantly higher than its precursors. The TROPOMI/S5P satellite data is publicly available via https://s5phub.copernicus.eu/. The spectrometer measures several trace gases including $\mathrm{NO}_{2}$. Since $\mathrm{NO}_{2}$ gas is the most prominent product of photochemical reactions of emitted $\mathrm{NO}_{\mathrm{x}}$, it can be used for the monitoring of the ships' emission compliance.

The positions of the ships were estimated based on resampling and interpolation of data obtained from AIS transponders ${ }^{1}$. The data include position, speed, heading and a unique identifier (MMSI) of the ship. For this study, the AIS data were provided by the Human Environment and Transport Inspectorate (ILT) of the Netherlands. Information about dimensions of the ships was retrieved from official ship registries.

The wind information was obtained from $10 \mathrm{~m}$ wind speed data of the European Center for Medium range Weather Forecast (ECMWF), available with $0.25^{\circ}$ resolution at 6-hourly timesteps.

\section{METHOD}

In this section we describe all steps of the proposed approach for automated evaluation of $\mathrm{NO}_{2}$ emission from individual ships.

\subsection{Image enhancement}

To increase the contrast between the ships' plumes and the background, we used spatial association statistic local Moran's I [2] one of the most often used methods for hot spot detection [13]. For an observation point or pixel $i$, the local Moran's $I$ is defined as follows:

$$
I_{i}=\frac{\left(x_{i}-\mu\right)}{\sigma^{2}} \sum_{j=1, j \neq i}^{N} w_{i j}\left(x_{j}-\mu\right),
$$

where $x_{i}$ is the value of the respective pixel, $N$ is the number of analyzed pixels, $\mu$ is a mean value of $N$ pixels, $\sigma^{2}=\frac{\sum_{i}\left(x_{i}-\mu\right)^{2}}{N}$ is an estimate of the variance, and $w_{i j}$ is a value of a binary spatial contiguity weight matrix $W$ at a location $j$ with regards to an analyzed pixel $i$. In this study, the queen spatial contiguity criterion [8] is applied. With this criterion two pixels are considered to be neighbors if they share either a common edge or a vertex. Figure 1 illustrates an example where the applied image enhancement procedure notably reduced the background noise and increased the contrast between the plume and the background, improving the detectability of the ships' traces.

\footnotetext{
${ }^{1}$ Since 2002 all sea-going vessels are obliged to carry on board AIS transponder [12]
}
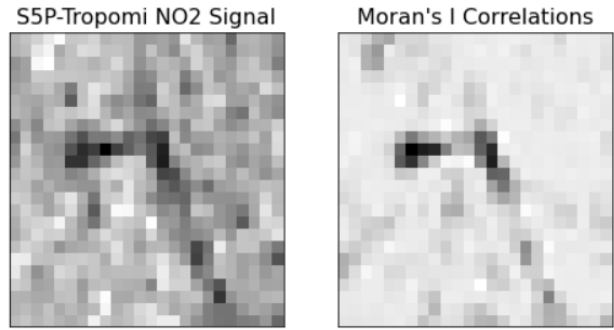

Figure 1: Reduction of the background noise as a result of application of the local Moran's $I$. Two plumes of different origin are depicted in each Figure.
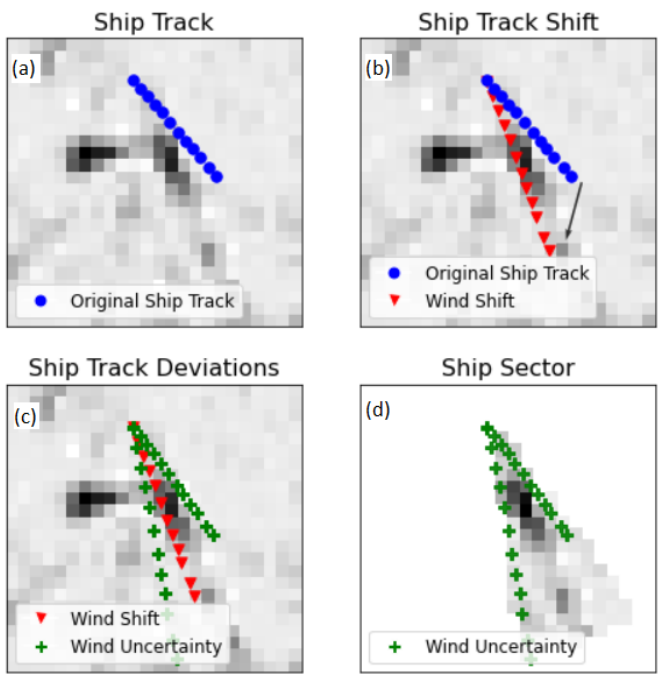

Figure 2: Construction of ship sector based on AIS ship position and wind data. (a) Track of the ship. (b) Ship track shifted according to the speed and the direction of the wind. Black arrow indicates the wind direction. (c) Wind-shifted ship track with the wind uncertainty applied. (d) Resulting ship sector.Since

\subsection{Ship-plume assignment and NO2 emission evaluation}

To determine the spatial correspondence between the TROPOMI signal and the ship's location is a challenging task. The emitted plume is displaced by the prevailing winds, so that observed $\mathrm{NO}_{2}$ concentrations no longer coincide with the tracks of the ships. At the same time, linear transformation of the ship trajectory that is solely based on available wind data (e.g. [7]) might be inaccurate due to the wind-related uncertainties (see Figure 2b). Such a method is further used for the benchmarking of our approach. We refer to it as ship track shift.

To overcome the problem of an inaccurate ship-plume matching, to each ship we assigned an area of interest, so-called "ship sector" (Figure 2d). The ship sector is defined based on wind-shifted track of the ship but also based on incorporated uncertainties in the speed 


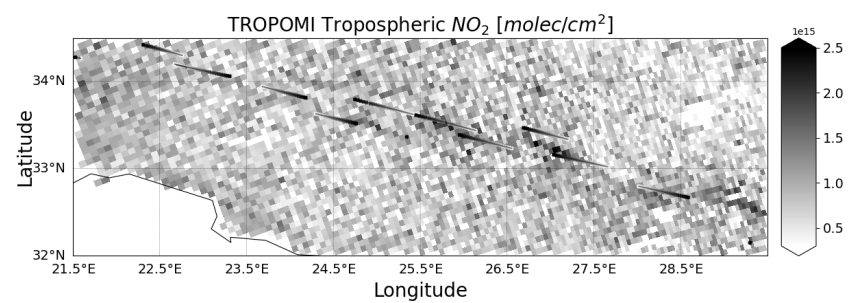

Figure 3: The $\mathrm{NO}_{2}$ tropospheric column. Black lines indicate ships' tracks based on information from AIS data.

and direction of wind (Figure 2c). Below we describe the parameters used for the ship sector definition. The parameters' values were chosen so that the quality of NO2 estimation is maximized for areas both in the Arabian and Mediterranean Sea.

The applied values of wind speed and wind direction uncertainties equal to $2 \mathrm{~m} / \mathrm{s}$ and $20^{\circ}$ respectively. The time prior the satellite overpass, needed to determine the point where the plume becomes too dispersed to study, equals to 1 hour for the Mediterranean Sea areas, and 40 minutes for the areas in the Arabian Sea. Such a discrepancy is most likely caused by the difference in atmospheric conditions of two studied regions.

Within each ship sector, we separated pixels that were determined as a plume by thresholding the enhanced image. The applied threshold equals to the $25^{\text {th }}$ percentile of the values of the pixels lying inside the sector. The average value of $\mathrm{NO}_{2}$ pixels determined as a plume held as the evaluation value of $\mathrm{NO}_{2}$ for the corresponding ship and was used for the comparison with the emission proxy that we describe in Subsection 3.3.

\subsection{Model performance evaluation}

For the validation of ship-plume assignment we used an $\mathrm{NO}_{\mathrm{x}}$ emission proxy proposed in [7]. The proxy is defined as:

$$
E_{s}=L_{s}^{2} \cdot U_{s}^{3},
$$

where $L_{s}$ is the length of the ship in $\mathrm{m}$, and $U_{s}$ is its speed in $\mathrm{m} / \mathrm{s}$.

The quality of ship-plume assignment was reported in terms of the Pearson correlation between the assigned value of $\mathrm{NO}_{2}$ and the emission proxy $E_{s}$ for all ships in an analyzed area. Note that the used simple model of emission proxy does not reflect all factors that are needed for a precise estimation of ship emission potential; thus it is not expected to lead to a perfect correlation with experimentally determined values of $\mathrm{NO}_{2}$.

\subsection{Data selection}

For the experiments, we chose six days with suitable weather conditions (wind $<6 \mathrm{~m} / \mathrm{s}$, low level of background pollution) in the Arabian and Mediterranean Sea (see Table 1). An example of an analyzed area can be found in Figure 3.

To ensure high quality of the satellite signal, the following filtering criteria were applied to TROPOMI data: qa_value $>0.5$, cloud fraction $<0.5$. For detailed description of the variables see [17].

Some pre-processing steps were applied to the AIS ship data. First, only ships with overall length exceeding $150 \mathrm{~m}$ and speed
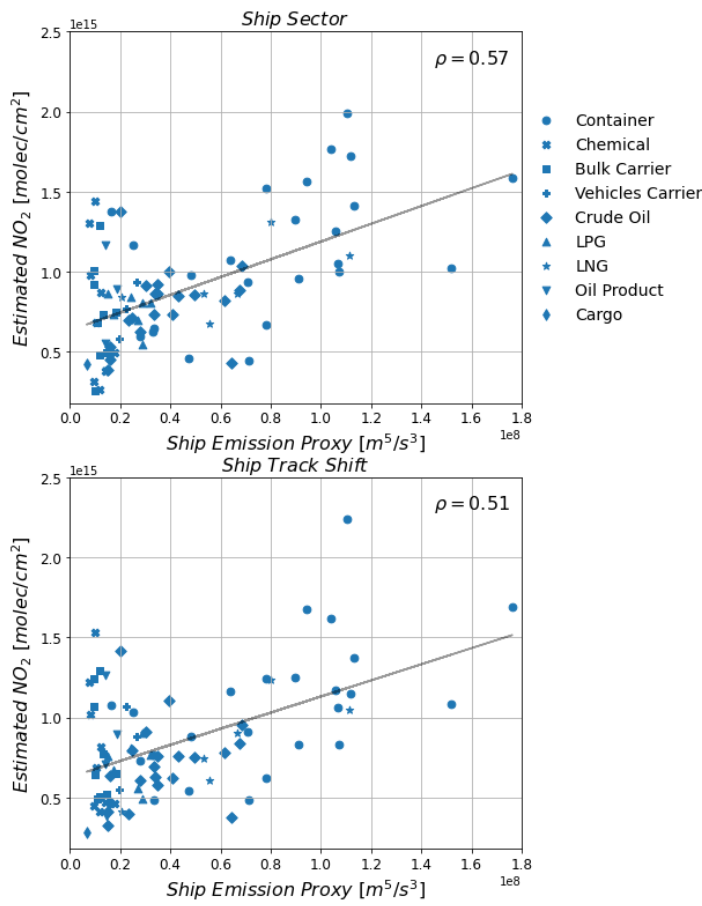

Figure 4: Aggregated correlation between the assigned $\mathrm{NO}_{2}$ values and the corresponding values of the emission proxy for the method proposed in this study (top) and the baseline approach (bottom). Markers indicate the ships' types.

above $12 \mathrm{kt}^{2}$ were taken into account. The emission level of smaller or slower ships is expected to be below the detection level of the satellite. Second, if the plume of a ship undergoes intersection with any other plume of sufficient concentration, the ship was excluded from the study.

\section{RESULTS}

We compared the results achieved with our approach with the baseline method of ship track shift [7] (see Table 1). For five out of the six analyzed areas the method proposed in this study led to improvement of the quality of the linear correlation between the estimated $\mathrm{NO}_{2}$ values and the emission proxy of the corresponding ship. The weighted mean value of the Pearson coefficient (the weights are the number of ships analyzed within each area) increased from 0.63 to 0.73 , whereas weighted standard deviation decreased from 0.13 to 0.09 .

Finally, we calculated an aggregated correlation of $\mathrm{NO}_{2}$ estimations for all six days analyzed with the associated emission proxies (see Figure 4). This allowed us to access generalization properties of the proposed approach. We can see that the level of achieved correlation decreased for both methods. This was expected and was mainly caused by the smaller ships, detectability of which is highly dependent on the satellite sensitivity at a given moment of time. Nevertheless, the approach proposed in our study still assures higher quality of the results.

\footnotetext{
${ }^{2} \mathrm{kt}$ - knot, a unit of speed equal to a nautical mile per hour. $12 \mathrm{kt} \approx 6.2 \mathrm{~m} / \mathrm{s}$.
} 


\begin{tabular}{|c|c|c|c|c|c|c|c|}
\hline Date & Region & Long range & Lat range & Ship sector & Ship track shift & Detected ships & Undetected ships \\
\hline 2019-04-02 & Mediterranean & $(21.5 ; 29.5)$ & $(32.0 ; 34.5)$ & 0.81 & 0.24 & 8 & 1 \\
\hline 2019-08-07 & Mediterranean & $(19.5 ; 27.0)$ & $(33.0 ; 35.0)$ & 0.61 & 0.60 & 17 & 1 \\
\hline 2019-09-27 & Mediterranean & $(20.0 ; 24.7)$ & $(32.5 ; 35.0)$ & 0.78 & 0.77 & 9 & 1 \\
\hline 2020-04-11 & Arabian & $(64.0 ; 69.0)$ & $(14.0 ; 18.0)$ & 0.83 & 0.67 & 15 & 1 \\
\hline 2020-05-01 & Arabian & $(64.0 ; 71.0)$ & $(14.0 ; 18.0)$ & 0.65 & 0.71 & 20 & 0 \\
\hline \multirow[t]{3}{*}{$2020-05-03$} & Arabian & $(64.0 ; 70.0)$ & $(12.0,18.0)$ & 0.80 & 0.63 & 16 & 2 \\
\hline & AVG/SUM: & & & 0.73 & 0.63 & 85 & 6 \\
\hline & STD: & & & 0.09 & 0.13 & & \\
\hline
\end{tabular}

Table 1: The Pearson correlation coefficients of assigned $\mathrm{NO}_{2}$ with with the corresponding value of the ship's emission proxy for each of analyzed scenes. The ship sector column corresponds with the results achieved with the method presented in this study. The ship track shift column shows the correlations obtained with the baseline method [7].

\section{CONCLUSIONS}

In this study we introduced a new approach for the automated evaluation of $\mathrm{NO}_{\mathrm{x}}$ emissions of individual seagoing ships with TROPOMI/S5P satellite data. We applied a spatial association statistic, local Moran's $I$, to enhance the separability between the ships' plumes and the background. We further proposed a new method for automated ship-plume matching. Using uncertainties in speed and direction of the wind data, the method defines for each ship an region of interest - a ship sector. In this sector, the plume can be detected based on the local threshold.

We then compared the results obtained using our method with the approach proposed in a previous study. The comparison showed that our method leads to the increment of the linear correlation between estimated values of $\mathrm{NO}_{2}$ and model-based emission proxy for five over the six analyzed areas, as well as for an aggregated experiment, where the Pearson correlation was calculated for all six analyzed areas at once. We can conclude that the proposed approach assures more precise quantification of local $\mathrm{NO}_{2}$ concentrations caused by $\mathrm{NO}_{\mathrm{x}}$ emissions of individual ships. Moreover, the method introduced in this study does not require any manual steps what is a significant improvement over the current state-of-the-art.

\section{ACKNOWLEDGMENTS}

This work is funded by the Netherlands Human Environment and Transport Inspectorate, the Dutch Ministry of Infrastructure and Water Management, and the SCIPPER project, which receives funding from the European Union's Horizon 2020 research and innovation programme under grant agreement Nr.814893.

\section{REFERENCES}

[1] Harshit Agrawal, Quentin GJ Malloy, William A Welch, J Wayne Miller, and David R Cocker III. 2008. In-use gaseous and particulate matter emissions from a modern ocean going container vessel. Atmospheric Environment 42, 21 (2008), 5504-5510.

[2] Luc Anselin. 1995. Local indicators of spatial association-LISA. Geographical analysis 27, 2 (1995), 93-115.

[3] Jörg Beecken, Johan Mellqvist, Kent Salo, Johan Ekholm, and J-P Jalkanen. 2014 Airborne emission measurements of $\mathrm{SO} 2, \mathrm{NO} x$ and particles from individual ships using a sniffer technique. Atmospheric Measurement Techniques 7, 7 (2014), 1957-1968.

[4] S Beirle, U Platt, R Von Glasow, M Wenig, and T Wagner. 2004. Estimate of nitrogen oxide emissions from shipping by satellite remote sensing. Geophysical Research Letters 31, 18 (2004)
[5] K Folkert Boersma, Geert CM Vinken, and Jean Tournadre. 2015. Ships going slow in reducing their NOx emissions: changes in 2005-2012 ship exhaust inferred from satellite measurements over Europe. Environmental Research Letters 10, 7 (2015), 074007.

[6] James J Corbett, James J Winebrake, Erin H Green, Prasad Kasibhatla, Veronika Eyring, and Axel Lauer. 2007. Mortality from ship emissions: a global assessment. Environmental science \& technology 41, 24 (2007), 8512-8518.

[7] Aristeidis K Georgoulias, K Folkert Boersma, Jasper van Vliet, Xiumei Zhang, Prodromos Zanis, Jos de Laat, et al. 2020. Detection of NO2 pollution plumes from individual ships with the TROPOMI/S5P satellite sensor. Environmental Research Letters 15, 12 (2020), 124037.

[8] Arthur Getis and Jared Aldstadt. 2004. Constructing the spatial weights matrix using a local statistic. Geographical analysis 36, 2 (2004), 90-104.

[9] IMO. 2020. MARPOL ANNEX VI - regulation 13. https://www.imo.org/ en/OurWork/Environment/Pages/Nitrogen-oxides-(NOx)-\%E2\%80\%93Regulation-13.aspx

[10] Daniel A Lack, James J Corbett, Timothy Onasch, Brian Lerner, Paola Massoli, Patricia K Quinn, Timothy S Bates, David S Covert, Derek Coffman, Berko Sierau, et al. 2009. Particulate emissions from commercial shipping: Chemical, physical, and optical properties. Journal of Geophysical Research: Atmospheres 114, D7 (2009).

[11] Robert McLaren, Patryk Wojtal, Jamie D Halla, Cris Mihele, and Jeffrey R Brook. 2012. A survey of NO2: SO2 emission ratios measured in marine vessel plumes in the Strait of Georgia. Atmospheric environment 46 (2012), 655-658.

[12] Jun Min Mou, Cees Van der Tak, and Han Ligteringen. 2010. Study on collision avoidance in busy waterways by using AIS data. Ocean Engineering 37, 5-6 (2010), 483-490.

[13] J Keith Ord and Arthur Getis. 1995. Local spatial autocorrelation statistics: distributional issues and an application. Geographical analysis 27, 4 (1995), 286306.

[14] Andreas Paxian, Veronika Eyring, Winfried Beer, Robert Sausen, and Claire Wright. 2010. Present-day and future global bottom-up ship emission inventories including polar routes. Environmental science \& technology 44, 4 (2010), 13331339.

[15] Andreas Richter, Veronika Eyring, John P Burrows, Heinrich Bovensmann, Axel Lauer, Bernd Sierk, and Paul J Crutzen. 2004. Satellite measurements of NO2 from international shipping emissions. Geophysical Research Letters 31, 23 (2004).

[16] SCIPPER. 2020. Shipping Contributions to Inland Pollution Push for the Enforcement of Regulations. https://www.scipper-project.eu/

[17] Maarten Sneep. 2021. Sentinel 5 precursor/TROPOMI KNMI and SRON level 2 Input Output Data Definition. Technical Report S5P-KNMI-L2-0009-SD.

[18] W Van Roy and K Scheldeman. 2016. Results MARPOL Annex VI Monitoring Report: Belgian Sniffer Campaign 2016. (2016).

[19] JP Veefkind, I Aben, K McMullan, H Förster, J De Vries, G Otter, J Claas, HJ Eskes, JF De Haan, Q Kleipool, et al. 2012. TROPOMI on the ESA Sentinel-5 Precursor: A GMES mission for global observations of the atmospheric composition for climate, air quality and ozone layer applications. Remote sensing of environment 120 (2012), 70-83.

[20] GCM Vinken, KF Boersma, A van Donkelaar, and L Zhang. 2014. Constraints on ship NO x emissions in Europe using GEOS-Chem and OMI satellite NO 2 observations. Atmospheric Chemistry and Physics 14, 3 (2014), 1353-1369. 